\title{
Effects of Most to Least Prompting Procedure on Teaching Exercise for Adults with Intellectual Disabilities*
}

\author{
Özgür Kurt ${ }^{1}$, Selmin Çuhadar ${ }^{2}$ \\ ${ }^{1}$ Trakya University, Institiute of Social Sciences, Department of Disability Studies, Balkan Campus, 22030 Edirne, \\ Turkey \\ ${ }^{2}$ Trakya University, Faculty of Education, Department of Special Education, 22100 Edirne, Turkey \\ Correspondence: Özgür Kurt, Trakya University, Institute of Social Sciences, Department of Disability Studies, Balkan \\ Campus, 22030 Edirne, Turkey.
}

$\begin{array}{lcc}\text { Received: July 11, } 2018 & \text { Accepted: July 25, } 2018 & \text { Online Published: July 26, } 2018 \\ \text { doi:10.11114/jets.v6i9a.3485 } & \text { URL: https://doi.org/10.11114/jets.v6i9a.3485 }\end{array}$

\begin{abstract}
In this research, the effectiveness of the most to least prompting instruction method in teaching dynamic stretching exercises to adults with intellectual disabilities has been evaluated. At the same time, the impact of this instruction on flexibility and balance which are among physical fitness components has also been determined. A single subject multiple baseline model across behaviors with probe conditions was used. Participants in the study were four women, 34-37 years old. The single opportunity method was used while collecting the data of the study, and all sessions were completed at the end of a period of 16-week. The results obtained from the study indicated that the most to least prompting method was influential in all the participants' learning about dynamic stretching exercises. At the same time, result of the evaluation of the pre-test and post-test measures revealed increases in flexibility and balance of the participants in various ratios. The results of the study indicate that the most to least prompting method was an influential method in teaching dynamic stretching exercises to adults with intellectual disabilities, making these exercises maintenance and generalization them. The results of the interviews conducted with teachers and parents in the study showed that the views of teachers and parents towards the most to least prompting method were positive.
\end{abstract}

Keywords: physical fitness, errorless teaching, single subject designs, disabled women

\section{Introduction}

Regular physical activity is important in terms of maintaining a healthy life for individuals with intellectual disabilities. Adult individuals with intellectual disabilities have a lower level of physical activity compared to their peers who show normal development. As in individuals with normal development, a lifestyle without sports activities increases over time the negative impacts on individuals with intellectual disabilities. The inactive lifestyle causes the individuals with intellectual disabilities to progressively lose balance and flexibility. This brings with it an increasingly immobile life and in time, individuals with intellectual disabilities become increasingly inclined to acquire diseases such as obesity, chronic heart disease, hypertension, stroke, diabetes, and various types of cancer (Carmeli et al., 2012; Dairo et al., 2016; Jansen et al., 2004; Lin et al., 2010). According to the findings of the review by Dairo et al., (2016) it is vital to increase the physical activity levels of the intellectual disability population. At the same time, lack of sports activities and exercises negatively affects many areas of daily life. The only purpose of directing individuals with intellectual disabilities to sports activities is not to protect their physical health, but also to improve their social skills and increase their life satisfaction in this way. On the other hand, depending on the degree of disabilities that the individual has, and all the other factors, visible losses occur in motor function of individuals with intellectual disabilities over time. A significant ratio of individuals with intellectual disabilities has low muscle tone, poorly developed postural adjustments, and balance reactions. This causes some problems for the individual to control his movements against gravity and to feel confident while moving (Sullivan, 2005). This also causes problems in physical fitness components such as body composition, agility, balance, and flexibility of individuals with intellectual disabilities and negatively affects their ability such as walking, climbing up- down stairs. In addition, this

\footnotetext{
*This study has been derived from master thesis of the first author' completed at Trakya University Institute of Social Science with supervising of the second author.
} 
makes it difficult for the individuals to carry out the most basic self-care skills or everyday life skills (e.g., bending to do up shoelace or to wear socks, getting on/ off a public transport vehicle, using the toilet, setting the table for dinner, etc.), or causes individuals inability to perform these skills appropriately. As a result of this, the quality of life of both the intellectual disabilities individual and his/her family are negatively affected by this process and this causes them to be isolated from the society they live in and daily life.

Regular physical activity has vital preventive measures for adult individuals with intellectual disabilities. In the related literature is placed on the importance of exercising necessity and benefits exercising for individuals with intellectual disabilities (Bartlo \& Klein, 2011; Golubović et al., 2012; Lin et al., 2010; Wu et al., 2010; Y1lmaz et al., 2014). However, in most of the studies in the literature on exercise teaching for adults with intellectual disabilities, researchers mainly used traditional teaching methods and experimental or quasi-experimental research methods (Bartlo \& Klein, 2011; Golubović et al., 2012; Lin at al., 2010; Savucu et al., 2006; Wu et al., 2010; Y1lmaz et al., 2014). These studies have made important contributions to the literature beyond dispute, but when an evaluation is made in terms of the teaching methods used in these research, it is seen that the teaching methods in the research do not exactly coincide with the fact that the individuals with the incompetency show heterogeneous features. In other words, individuals with disabilities showed differences as a group within themselves and in terms of their individual characteristics. The reasons for these differences are: the degree of disability that the individual has and the educational needs that are emerging often show significant differences in terms of individuals with disabilities. For this reason, the learning processes of these individuals with different characteristics have individual characteristics, which is very natural and necessary. In addition, the methodology adopted in evaluations made before and after teaching for each individual is also important. For this reason, it is also noteworthy and should not be forgotten that some aspects of individual performance and progress of the participants may have been overlooked in the results obtained from existing studies, often carried out using the experiments and control groups. However, it is stated in the literature that the use of systematic teaching processes, which are proven to be influential in the education of individuals with incompetence, is important in the individualization of teaching and in the individual evaluation of the participant's performance (Spooner et al., 2011; Tekin-İftar \& Kırcaali-İftar, 2006; Tekin-İftar, 2008; Yanardağ et al., 2008).

In literature, errorless teaching method effectiveness has been proved and in sports activities are taught (Altenbach-Brennan, 2010; Yanardağ et al., 2008; Yanardağ et al., 2011; Yılmaz, et al., 2010; Yılmaz et al., 2005; Yllmaz et al., 2005; Zhang et al., 2004). One of these errorless teaching methods is the most to least prompting method (Altenbach-Brennan, 2010; Yanardağ, et al., 2008; Yanardağ et al., 2015; Yılmaz et al., 2010). In the most to least prompting method, the practitioner performs the instruction by following a prompt hierarchy from the prompt which requires the most control (least moderate) to the prompt which requires the least control (the most moderate one). Initially, the least moderate prompt is presented concurrently with the target stimulus until the individual exhibits performance at a level that meets a certain criterion. After meeting the criterion at this level, the more moderate prompt is introduced and over time, it is made possible for the individual to exhibit the ability independent of prompts (Tekin-İftar \& Kircaali-Iftar, 2006). Among the research carried out in the literature by the most to least prompting method is teaching simple progression swimming skill by Yllmaz et al., (2010) Altenbach-Brennan, (2010) aquatic skills, Yanardağ et al., (2008) on ball playing skills, Yanardağ et al., (2015) movement exploration skills in water. As a result, in all of these studies, it is concluded that the most to least prompting method is rather effective in the teaching of sports activities to individuals with competencies. Participants in all of these research were young children. However, it has been stated in the literature that the most to least prompting method can be used effectively for younger and older individuals (Tekin-Iftar \& Kırcaali-İftar, 2006). For all these reasons, it is thought that it is important to investigate the effectiveness on the exercise instruction for adult individuals with intellectual disabilities by the most to least prompting method for which findings have been obtained for its affectivity in teaching individuals with intellectual disabilities different sports activities. In this study, the effectiveness of the most to least prompting method in the teaching of dynamic stretching exercises to adults with intellectual disabilities was evaluated. At the same time, the impact of this method on flexibility and balance which are among physical fitness components has also been determined.

\section{Method}

All of the participants in the study are women with intellectual disabilities. The ages of the participants vary between 34 and 37. All participants are students of the same adult education class of the state university at education and rehabilitation center. In order to be able to teach the participants the skills involved in the research, prerequisite skills required for the participants to have prior to the training are as follows:

(a) Imitating

(b) To follow and perform verbal instructions

(c) To have the necessary motor skills to be able to perform the exercises

(d) Not being the participant in a systematic teaching process in which the most to least prompting method was used. 
The presence of all prerequisite skills required for this study was observed by the practitioner in different environments and over time for all participants. All the participant who does not have any incompetence to do physical activities can easily use all parts of her body. They were not included in a systematic teaching process in which any of the errorless teaching methods were used. In addition, they did not continue any systematic exercise program before.

Helin is a 35-year-old woman with intellectual disabilities. She has been benefiting from special education and rehabilitation services provided by an official institution since the age of 20. During the research process, the participant continued to attend the same center for two days a week. The participant who has verbal communication skills can understand and fulfill the instructions made up of multiple steps. She does not have any problems in her social and communication skills. She is receiving epilepsy treatment. Nehir is a 35-year-old woman with intellectual disabilities. She has been benefiting from special education and rehabilitation services provided by an official institution for 15 years. The participant who has verbal communication skills can understand and fulfill the instructions made up of multiple steps. She does not have any problems in her social and communication skills. Raziye is a 37-year-old woman with intellectual disabilities. She has been benefiting from special education and rehabilitation services provided by an official institution for 15 years. However, during this period, she sometimes quitted attending the classes. The participant who has verbal communication skills can understand and fulfill the instructions made up of multiple steps. She does not have any problems in her social and communication skills. Serap is a 34-year-old woman with intellectual disabilities. She has been benefiting from special education and rehabilitation services provided by an official institution since the age of 2 . The participant who has verbal communication skills can understand and fulfill the instructions made up of multiple steps. She does not have any problems in her social and communication skills.

\subsection{Procedures and Experimental Design}

The procedure was started with obtaining consent of the participant's parents on behalf of their intellectual disabled children. The researchers gave each parent clear information face to face about the research. Parents who accepted to participate their children to the research gave their signed permission with a consent form. The research was also approved by institute board of the university. In the research, multiple baseline model between skills was used in determining the effectiveness of teaching dynamic stretching exercises by the most to least prompting method (Alberto \& Troutman, 1995; Tawney \& Gast, 1984). In the multiple baseline model between skills, similar target behaviors were chosen that are functionally independent from each other and that may change with the same practice. The dependent variables of the study are dynamic stretching exercises. The dynamic stretching exercises in this study were chosen among the exercises that participants are not familiar with in their daily lives but would support the basic physical activities in daily life activities. Bending to do up shoelace or to wear socks, getting on/ off a public transport vehicle, or taking something to the dinner table etc. can be counted as examples. For each of the exercises that were taught in the research, skills analysis was developed. The validity of the developed skill analyzes was also assessed by a different special education specialist. In addition, the original names of the exercises were adapted to the Turkish, which is the mother tongue of the participants, so that the participants could easily remember them (e.g., "Walk of a Soldier" for power high knee, "Walk of an Efe" for walking lunge, and "Butterfly Exercise- for the bent back rotation). The independent variable of the research is the most to least prompting method. The study includes baseline, instructional, maintenance, and generalization sessions.

\subsection{Flexibility and Balance}

Pre-test and post-test measurements of the balance were made with the "Modified Flamingo" balance test. This test was carried out using a special platform with $4 \mathrm{~cm}$ width, $5 \mathrm{~cm}$ thickness and $45 \mathrm{~cm}$ length which had two $4 \mathrm{~cm} \times 4 \mathrm{~cm} \times 15$ $\mathrm{cm}$ wooden legs vertically fixed to both ends. During this test, the participants were asked to stand in balance on one foot on the platform, arms adjacent to the body, and their eyes open. Participants were allowed to receive help from the trainer with a single hand until they were able stand in balance after taking a position on the platform. After balance was established and the participant joined her arms with the body, the time is started. The test is terminated when the arms are separated from the body and the foot touches the floor, and the participant's balance time is recorded. Pre-test and post-test measures of the flexibility were evaluated by the "Sit-stretch" test. The test was repeated twice after 30 seconds' breaks and the best value was considered as the level of flexibility. The stand measurements used to make the measurement are: (a) length $35 \mathrm{~cm}$, (b) width $45 \mathrm{~cm}$, (c) height $32 \mathrm{~cm}$.

\subsection{Baseline (A) Conditions}

Baseline sessions are probe sessions conducted prior to teaching target behaviors. The single opportunity method was used to collect data during all probe sessions. In the process of determining the performance level with the data collection tools, the participant was first assisted in gathering her attention and then given a task direction to perform the task. After the task direction was given, 5 seconds was waited for the participant's reaction. The absence of reaction or inadequate reaction to the situations involved in the participants' skill analyzes were recorded with a minus sign (-) in 
the data record form. The correct reactions of the participants were recorded with a plus $(+)$ sign in the data record form. For example, the trainer gathers the participant's attention by asking her "Helin, are you ready to do some exercise with me?" afterwards he receives a verbal or physical respond from the participant indicating that she is ready (e.g. "Yes, I am ready", or nodding her head yes), and then she is given a task direction "Helin, walk a soldier's walk". The trainer waited for the participant to react for 5-s after the task direction was given. When the participant responded correctly, it was marked with a (+) in the data collection form and another 5 seconds were waited for the next step to take place. The first incorrect reaction of the participant was recorded on the registration form with a (-) and the probe session was terminated. Prior to the start of teaching, to determine the baseline of participants' target behaviors, the baseline data were collected until three sessions of stable data were obtained.

\subsection{Most to Least Prompting Instructional Conditions}

The most to least prompting method was carried out in three stages. In the first stage, modeling and verbal prompts were used together. At this stage, the trainer and the participant stood side by side on the starting line, and the attention of the participant to work was gathered by saying, "Are you ready to do exercise, Helin?" After the trainer receives a verbal or physical reaction from the participant indicating that she is ready, he says "Watch me very carefully and do the same thing as I do now." Thus, he became the model for the first step of the skill to be taught and also gave the verbal prompt about the skill level at the same time. For example, when doing the walking lunge exercise, the trainer bends his right leg and steps forward while at the same time he says to the participant "bend your leg and step forward", and the trainer waits for the participant to do the same thing with maintaining his position. Upon the participant's doing the relevant skill level, the trainer gives the participant verbal reinforce like "well done, you did it right" and immediately after that he starts the other step of the relevant skill. The trainer gathers the participant's attention by saying "All right, now we are going on" and bends his left leg, steps forward while saying to the participant "bend the other leg and step forward". In the second stage, verbal prompts were provided for teaching the skill steps. After the trainer gave the verbal cue, he waited for the participant to react for 5-s for each step. At the last stage, the trainer gathers the participant's attention by saying to the participant, "Helin, are you ready to do exercise with me?" and after receiving either verbal or physical response from the participant indicating that she is ready, he says "Helin, do the efe walk" and gives the target stimulus of the skill in the form of a skill instructor. After all stages of skill have been successfully completed and the criteria have been met, the teaching is continued in the same manner, with the next skill being taught. After meeting the criteria for all skills, the teaching sessions were terminated. During the teaching sessions, basically three different participant reactions were evaluated. These are the correct reaction, the incorrect reaction and lack of reaction. The correct response is defined as the attempt to complete the skill step and complete the skill step within 5-s after the prompt has been given. Correct answers were recorded as (+) and negative answers as (-) during teaching sessions. By repeating all the exercises from the specified starting point to the ending point, each exercise is performed at a specified number of times.

\subsection{Trainers}

The implementation process was carried out by the first author, who has bachelor degree in physical education teaching and who continued his postgraduate education in an interdisciplinary program related to special education. The researcher has experience in providing training to individuals with intellectual disabilities. Moreover, the first author was informed theoretically and practically about the most to least prompting method by the second author, and sample teaching sessions were conducted under the guidance of the second author until the first author achieved $100 \%$ success in the teaching process.

\subsection{Settings}

All probe, instructional, and maintenance sessions occurred at the state university college of physical education and sports rhythm training dance hall. The hall is of $12 \mathrm{~m} \times 6 \mathrm{~m}$ sizes. There are 3 mirrors of $2 \mathrm{~m} \times 1.5 \mathrm{~m}$ sizes on one of the walls, on which participants can watch themselves. In order to lighten the hall and to let fresh air in the hall, there are 4 windows of $30 \mathrm{~cm} \times 30 \mathrm{~cm}$ sizes on one of the walls close to the ceiling. All the sessions of the study were conducted with one-to-one instruction method and all the sessions of the study were completed after a 16-week period. The sessions were organized two days a week in the morning and afternoon. Morning sessions were held between 09.00 and 11.00 and afternoon sessions were between 14.00 and 16.00. Only one session was held with the same participant on the same day.

\section{Materials}

In the research process, "Modified Flamingo Balance" and "Sit-Up Flexibility" tools were used to perform pre-test and post-test evaluations of flexibility and balance of the physical fitness components. Participants were dressed in sportswear suitable for exercising throughout the entire study period. Additionally, throughout the research, video camera, video camera recording forms and pen for data recording were used. Throughout the research process, every correct behavior of the participants was reinforced with verbal reinforcements such as "Good work! Congratulations! 
You are doing great! and You did it right". At the end of each implementation, when participants exhibited a performance that met the criteria, each participant's own choice of activity (such as going to the cinema, sitting in the café, or spending time in the cafeteria of the university) was carried out together with the practitioner.

\subsection{Data Collection}

\subsubsection{Reliability}

Interobserver reliability data were collected during at least $20 \%$ of all experimental sessions. Interobserver reliability (depended variable reliability) was calculated by using point by point method with a formula of number of agreements dived by the number of agreements plus disagreements multiplied by 100 (Tawney \& Gast, 1984). The interobserver reliability of this study was found to be $90 \%(80 \%-100 \%)$. Procedural reliability data were collected during at least $30 \%$ of all experimental sessions. Procedural reliability (Independent variable reliability) was calculated by dividing the number of teachers behaviors observed by the number of teachers behaviors planned and multiplied by 100 (Billingsley, White, \& Munson, 1980). Independent variable reliability (procedural reliability) was calculated by dividing the number of teacher behaviors observed by the number of teacher behaviors planned and multiplied by 100 (Billingsley, White, \& Munson, 1980). The following basically behavior were observed for procedural reliability during training session: (a) arranging materials, (b) gathering the participant's attention, (c) presenting the task direction, (d) presenting the controlling prompt in time, (e) waiting during the response interval, and (f) reinforcing correct behaviors. The teacher showed $100 \%$ compliance with the steps of each experimental session across four participants.

\subsubsection{Social Validity}

In order to collect social validity data, semi-structured interview questionnaires, composed of different questions for teachers and parents, were prepared. After the interview forms were prepared, interviews were held with the teacher and the parents at the appointed day and after the research finished. Teachers and parents watched separately the participant images at the beginning of the research and after the teaching ended. In addition to the use of questionnaires in the interviews, voice recording was also done during the interviews. Since all participants were educated in the same class, a single interview was held with the participants' teacher during the collection of social validity data. However, the teacher watched the images of the participants both at the beginning and at the end of the research separately for each participant and questions about all participants were asked to the teacher during the interview.

\subsection{Maintenance and Generalization Sessions}

Maintenance sessions were held two weeks after the end of the program to determine the extent to which participants maintained what they had learned. Pre-test and post-test sessions on generalization were conducted in a suitable room in the center by the teacher. The pre-test generalization session was held prior to the baseline and the post- test generalization session was held after the end of the teaching. The process in the generalization sessions was similar to the probe sessions.

\section{Results}

\subsection{Most to Least Prompting Instructional Data}

Table 1 shows the criterion and number of sessions for each participant. Each participants attained a determined level of dynamic stretching exercises at the end of 13 instructional sessions. When instruction of the dynamic stretching exercises using "modelling and verbal prompt" started, they performed with accuracy in the first five session, and continued their performance while using "verbal prompt" in sessions 6, 7, 8, 9, 10. All participants' performance continued in sessions 11, 12, 13 while using only task direction for independent sessions. Results of the study were analyzed using graphic illustrations. The closed circles represent the percentage of correct responses during the probe, teaching, and maintenance sessions. This data showed that most to least prompting was effective on teaching dynamic stretching exercises for all participants. Figures 1, 2, 3, and 4, show the percentage of correct responses of the participants during the probe and training sessions for Participant 1,2,3, and 4, respectively. As seen in Figures 1 through 4, all the participants increased their correct behaviors in the dynamic stretching exercises after the introduction of most to least prompting procedure. The data obtained from the graphs indicate that most to least prompting instruction method was effective in teaching the dynamic stretching exercises to the all participants.

Table 2 shows that all the participants percentage of correct responses for baseline and instructional sessions. Additionally, during the maintenance sessions, all participants were observed to be performing at a satisfactory level in all skills taught. 
Table 1. Each participants through Criterion and Number of Sessions

\begin{tabular}{|c|c|c|c|}
\hline Participants & Skills & Through Criterion & Number of Sessions \\
\hline Helin & $\begin{array}{l}\text { Dynamic stretching } \\
\text { exercises* }\end{array}$ & $\begin{array}{l}\text { Modeling }+ \text { Verbal prompt } \\
\text { Verbal prompt } \\
\text { Independent } \\
\text { Total }\end{array}$ & $\begin{array}{l}5 \\
5 \\
3 \\
13\end{array}$ \\
\hline Nehir & $\begin{array}{l}\text { Dynamic stretching } \\
\text { exercises }\end{array}$ & $\begin{array}{l}\text { Modelling + Verbal prompt } \\
\text { Verbal prompt } \\
\text { Independent } \\
\text { Total }\end{array}$ & $\begin{array}{l}5 \\
5 \\
3 \\
13\end{array}$ \\
\hline Raziye & $\begin{array}{l}\text { Dynamic stretching } \\
\text { exercises }\end{array}$ & $\begin{array}{l}\text { Modelling + Verbal prompt } \\
\text { Verbal prompt } \\
\text { Independent } \\
\text { Total }\end{array}$ & $\begin{array}{l}5 \\
5 \\
3 \\
13\end{array}$ \\
\hline Serap & $\begin{array}{l}\text { Dynamic stretching } \\
\text { exercises }\end{array}$ & $\begin{array}{l}\text { Modelling + Verbal prompt } \\
\text { Verbal prompt } \\
\text { Independent } \\
\text { Total }\end{array}$ & $\begin{array}{l}5 \\
5 \\
3 \\
13\end{array}$ \\
\hline
\end{tabular}

*Note: Dynamic stretching exercises: power high knee; walking lunge; bent back rotation; backward high knee; back rotation. 


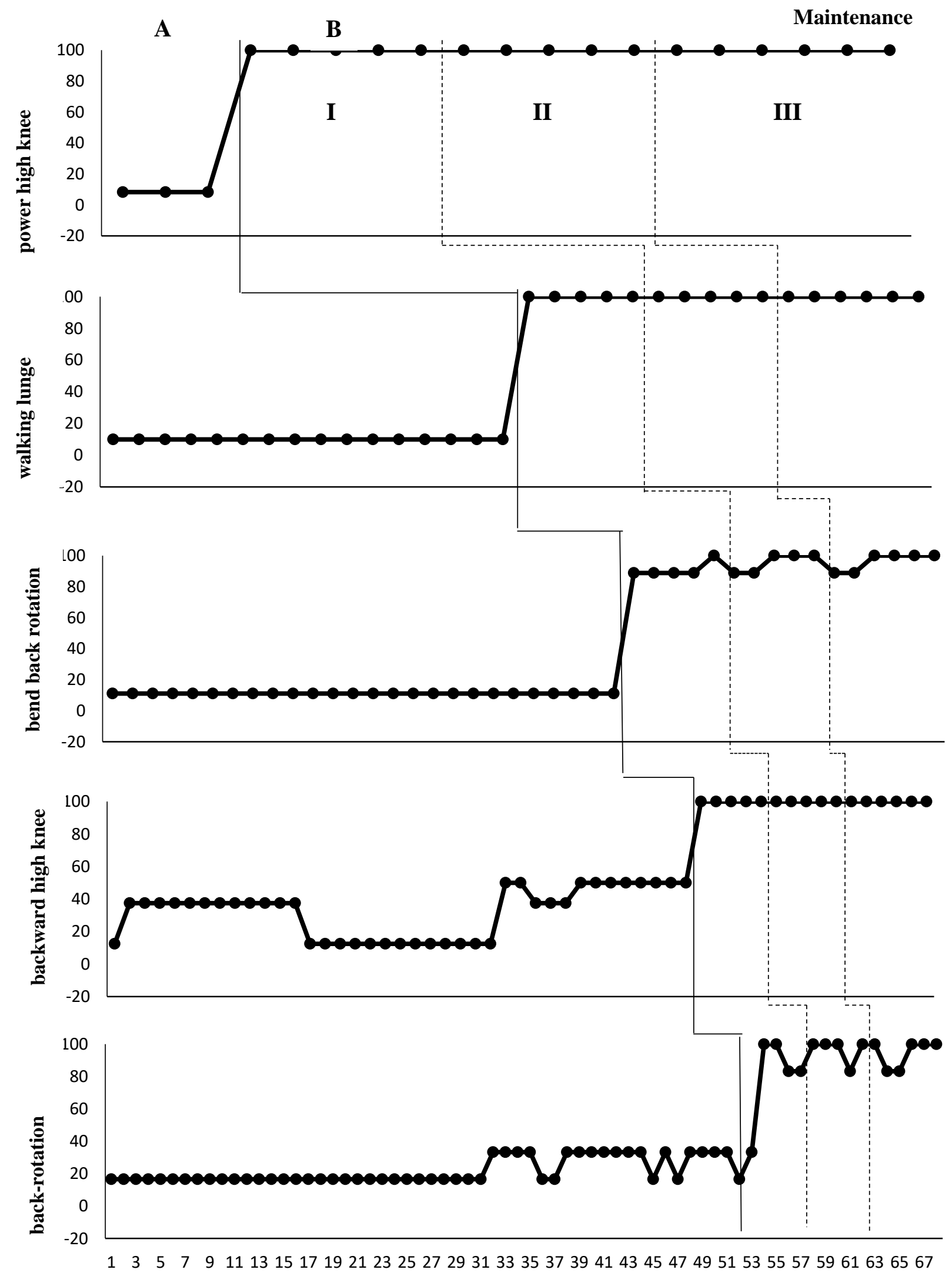

Figure 1. Percentage of correct responses for Helin during baseline (A), instructional (B), and maintenance sessions 
A

B

Maintenance

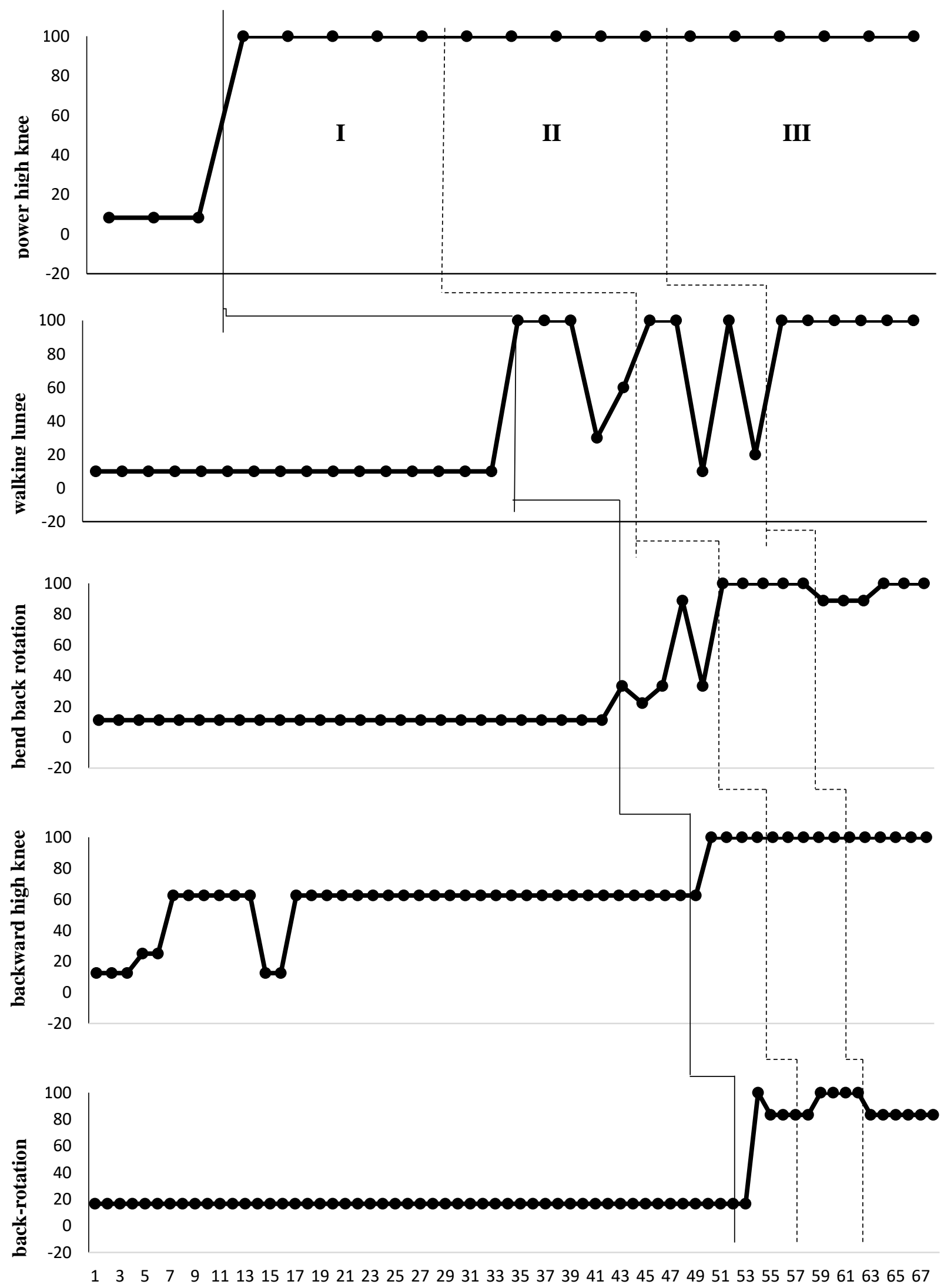

Figure 2. Percentage of correct responses for Nehir during baseline (A), instructional (B), and maintenance sessions 
A

B

Maintenance
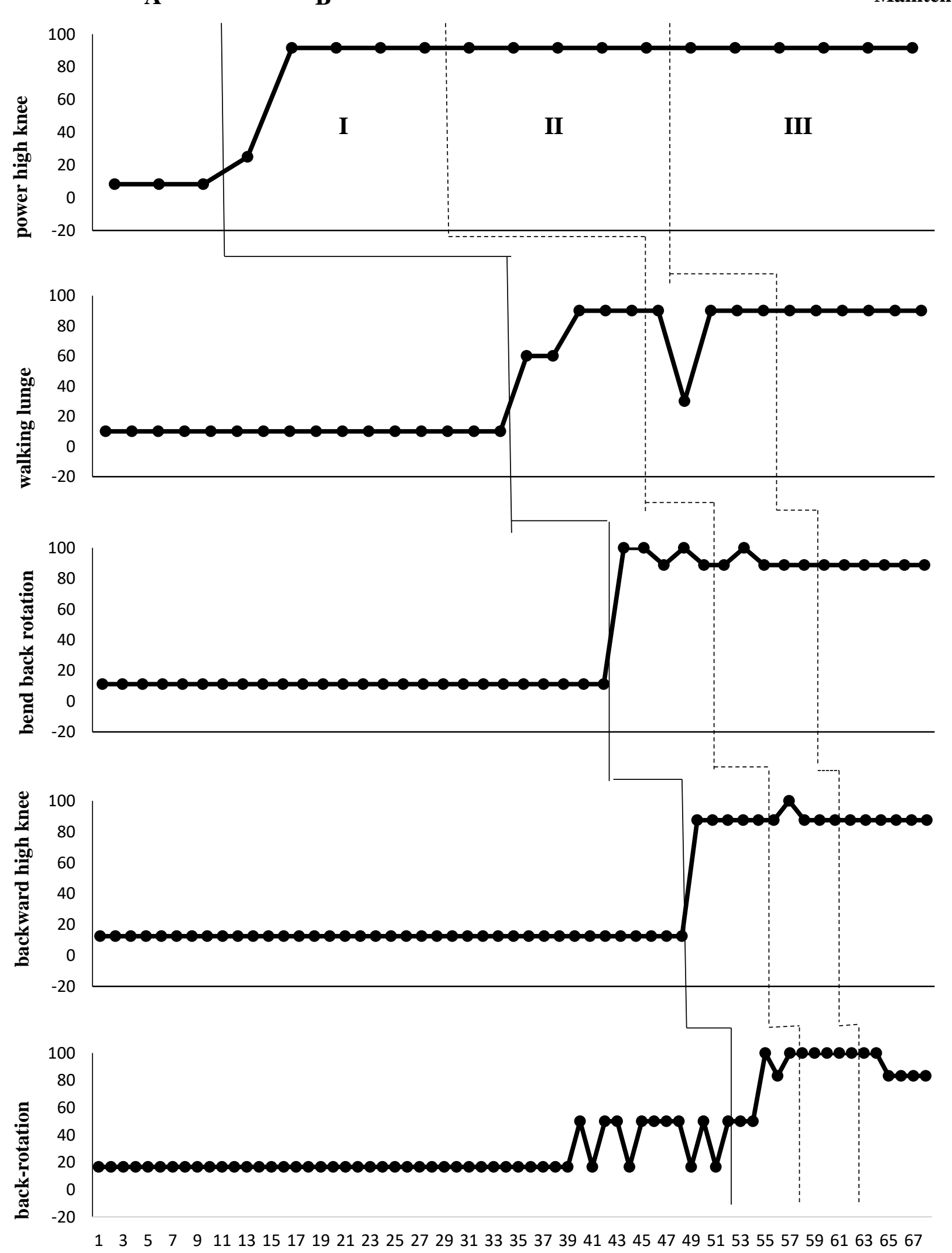

Figure 3. Percentage of correct responses for Raziye during baseline (A), instructional (B), and maintenance session 
A

B

Maintenance
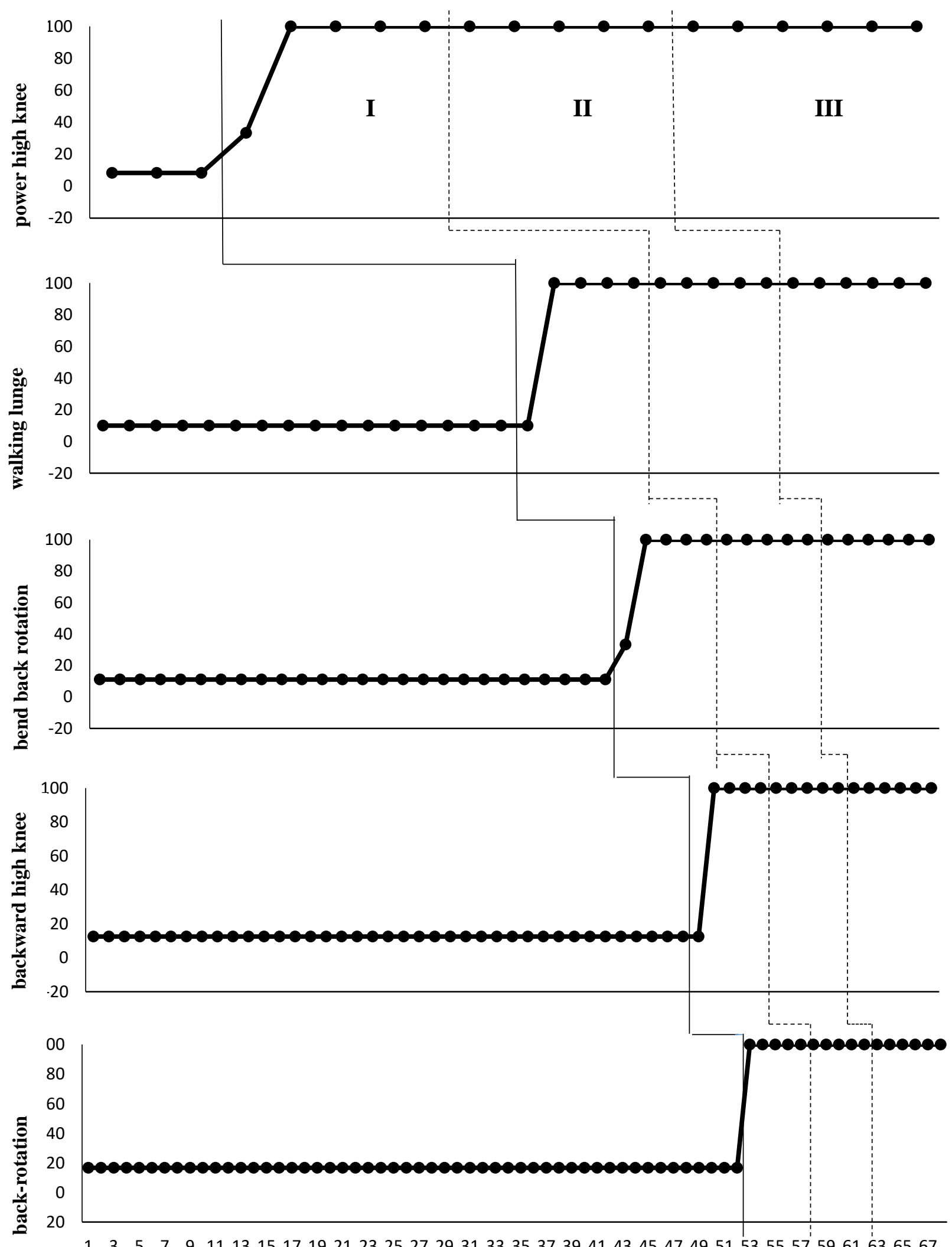

$1 \quad 3 \quad 5 \quad 7 \quad 91113151719212325272931333537394143454749515355575961636567$

Figure 4. Percentage of correct responses for Serap during baseline (A), instructional (B), and maintenance sessions 
Table 2. Percentages of Correct Responses for Each Participants during Baseline and Instructional Sessions

\begin{tabular}{|c|c|c|c|c|c|}
\hline \multirow[t]{2}{*}{ Participants } & \multirow[t]{2}{*}{ Skills } & \multirow[t]{2}{*}{$\begin{array}{c}\text { Baseline } \\
\text { (A) }\end{array}$} & $\begin{array}{l}\text { Instruction } \\
\text { (B) }\end{array}$ & \multirow[b]{2}{*}{ Verbal prompt II } & \multirow[b]{2}{*}{$\begin{array}{l}\text { Independent } \\
\text { III }\end{array}$} \\
\hline & & & Modelling+Verbal prompt I & & \\
\hline Helin & $\begin{array}{l}\text { Power high knee } \\
\text { Walking Lunge } \\
\text { Bend Back Rotation } \\
\text { Backward high knee } \\
\text { Back rotation }\end{array}$ & $\begin{array}{l}8 \% \\
10 \% \\
11 \% \\
32 \% \\
22 \% \\
\end{array}$ & $\begin{array}{l}100 \% \\
100 \% \\
93 \% \\
100 \% \\
80 \% \\
\end{array}$ & $\begin{array}{l}100 \% \\
100 \% \\
95 \% \\
100 \% \\
97 \% \\
\end{array}$ & $\begin{array}{l}100 \% \\
100 \% \\
93 \% \\
100 \% \\
89 \% \\
\end{array}$ \\
\hline Nehir & $\begin{array}{l}\text { Power high knee } \\
\text { Walking Lunge } \\
\text { Bend Back Rotation } \\
\text { Backward high knee } \\
\text { Back rotation }\end{array}$ & \begin{tabular}{l|}
$8 \%$ \\
$10 \%$ \\
$11 \%$ \\
$54 \%$ \\
$17 \%$ \\
\end{tabular} & $\begin{array}{l}100 \% \\
78 \% \\
42 \% \\
93 \% \\
73 \% \\
\end{array}$ & \begin{tabular}{l|}
$100 \%$ \\
$68 \%$ \\
$100 \%$ \\
$100 \%$ \\
$97 \%$ \\
\end{tabular} & $\begin{array}{l}100 \% \\
89 \% \\
89 \% \\
100 \% \\
83 \% \\
\end{array}$ \\
\hline Raziye & $\begin{array}{l}\text { Power high knee } \\
\text { Walking Lunge } \\
\text { Bend Back Rotation } \\
\text { Backward high knee } \\
\text { Back rotation } \\
\end{array}$ & $\begin{array}{l}8 \% \\
10 \% \\
11 \% \\
13 \% \\
22 \% \\
\end{array}$ & $\begin{array}{l}78 \% \\
78 \% \\
96 \% \\
88 \% \\
77 \% \\
\end{array}$ & $\begin{array}{l}92 \% \\
78 \% \\
91 \% \\
90 \% \\
100 \% \\
\end{array}$ & $\begin{array}{l}92 \% \\
90 \% \\
89 \% \\
88 \% \\
94 \% \\
\end{array}$ \\
\hline Serap & $\begin{array}{l}\text { Power high knee } \\
\text { Walking Lunge } \\
\text { Bend Back Rotation } \\
\text { Backward high knee } \\
\text { Back rotation }\end{array}$ & $\begin{array}{l}8 \% \\
10 \% \\
11 \% \\
13 \% \\
17 \%\end{array}$ & $\begin{array}{l}95 \% \\
93 \% \\
95 \% \\
93 \% \\
100 \%\end{array}$ & $\begin{array}{l}100 \% \\
100 \% \\
91 \% \\
100 \% \\
100 \%\end{array}$ & $\begin{array}{l}100 \% \\
100 \% \\
91 \% \\
100 \% \\
100 \%\end{array}$ \\
\hline
\end{tabular}

The pre-test and post-test results of the participants in terms of flexibility and balance characteristics are presented in Table 2. When the results of the measurements made before the teaching of the dynamic stretching exercises with the measurements made after the teaching of these exercises were compared, an increase in the flexibility abilities of all the participants other than Serap can be seen. Serap's pre-test and post-test measurements did not show any increase or decrease; instead, they remained the same. Measurements for the balance ability showed that the post-test measurements increased in all participants other than the Raziye, but there was no increase or decrease between the pre-test and post-test measures of Raziye. The pre and post-test measurements of Raziye also remained the same. When we evaluate the measurements in general, it can be said that the most to least prompting instruction method caused a positive change on the flexibility and balance measurements of the participants.

Table 3. Flexibility and Balance Characteristics of the Participants Pre-post Training

\begin{tabular}{|c|c|c|c|c|c|}
\hline Participants & $\begin{array}{l}\text { Flexibility pre-test } \\
(\mathrm{cm})\end{array}$ & $\begin{array}{l}\text { Flexibility } \\
(\mathrm{cm})\end{array}$ & post-test & $\begin{array}{l}\text { Balance pre-test } \\
\text { (sec.) }\end{array}$ & $\begin{array}{l}\text { Balance post-test } \\
\text { (sec.) }\end{array}$ \\
\hline Helin & 5 & 8 & & 3 & 10 \\
\hline Nehir & 0 & 1 & & 4 & 8 \\
\hline Raziye & 1 & 5 & & 3 & 3 \\
\hline Serap & 2 & 2 & & 3 & 5 \\
\hline
\end{tabular}

\section{Discussion}

The purpose of this study is to determine the effectiveness of the most to least prompting instruction method in the teaching dynamic stretching exercises for adult individuals with intellectual disabilities. Data related to maintenance and generalization was also collected, and teacher and parent opinions on this method in the teaching of dynamic stretching exercises were also determined. In addition, data were collected about the changes the skills that were taught in the research caused in the participants' flexibility and balance measurements, which are among physical fitness components. The findings of the study showed that the most to least prompting instruction method was effective in teaching dynamic stretching exercises to adults with intellectual disabilities and that the participants were still able to perform the skills they were taught two weeks after the teaching ended. It was also seen that all the participants were able to generalize their skills. Moreover, the post-test flexibility measurements of all the participants except Serap and the post-test balance measurements of all the participants except Raziye showed increase at different levels compared with the pre-test measurements. In a literature scanning made by Bartlo \& Klein (2011), moderate and strong evidence was found that physical activity positively affects balance, muscle strength and quality of life of individuals with intellectual disabilities.

In the literature, there are research on teaching different sports activities by systematic teaching processes to individuals 
with developmental disabilities. However, the participants of these research are generally younger children (Altenbach-Brennan, 2010; Yanardağ et al., 2011; Yanardağ, et al., 2015; Y1lmaz et al., 2005a; Y1lmaz et al., 2005b; Yllmaz et al., 2010). For this reason, it is considered that the current research has made significant contributions to the systematic teaching of adult individuals with special needs in the field. At the same time, this research is thought to be important since it is a research conducted using systematic teaching processes proved to be effective in providing education for individuals with special needs instead of using traditional teaching methods, unlike the existing research in which sports activities were taught to adult individuals with intellectual disabilities (Bartlo, \& Klein, 2011; Golubović et all, 2012; Lin et all, 2010; Savucu et al, 2006; Ün et all, 2001; Wu et all, 2010; Y1lmaz et al, 2014). In addition to these differences, the implementation reliability obtained in the study (100\%) shows a great degree of consistency with the findings of other research in which the most to least prompting instructional method is used in the literature (Altenbach-Brennan, 2010; Yanardağ et al., 2008; Yanardağ et al., 2015; Yılmaz et al., 2010). In the literature, it is recommended that the ideal implementation reliability coefficient be at least $80 \%$, preferably $90 \%$, and above (Wolery, Bailey, \& Sugai, 1988). The high implementation reliability data obtained in all studies strengthens the impression that practitioners can generally achieve high implementation reliability percentages with this method. It is thought that this application, which can be used with high implementation reliability by practitioners, can be used frequently to offer instruction to individuals with special needs (Altenbach-Brennan 2010; Yanardağ et al., 2008; Yanardag et al., 2015; Yilmaz et al. 2010).

One of the important contributions of this present study to the literature is that it supports the findings that the most to least prompting instructional method is effective in teaching different skills as well as in teaching sport skills to the individuals with disabilities (Altenbach-Brennan 2010; Yanardağ et al 2008; Yanardağ et al., 2015; Y1lmaz et al. 2010). The research was conducted using the multiple baseline models, one of the single subject research. In order to provide experimental control in the multiple baseline models, continuous baseline data were collected for the skills that had not yet been taught. In the study, in the baseline data collected continuously as required by the method, increase was observed at some sessions in Helin, Raziye, and Nehir's backward high knee and back rotation skills baseline data. Although these increases are not at a level that will adversely affect the teaching process, it is thought that sharing some predictions about this situation is important for future research. It is assumed that this was due to the adaptation of the exercises from their original names. During the long time ongoing baseline sessions, especially the words used during the adaptation of the original names of the exercises to the mother tongue of the participants became prompts for some participants. For example, saying "soldier's walk" for "power high knee" or "step high" for "backward high knee" connoted for the participants as to what the expected skills are. It is thought that the fact that the participants were adult individuals and their learning characteristics were also partly influential in these connotations.

Another important point in this study is the selection of prompts and dynamic stretching exercises. When the appropriate prompts were determined in the research process, it was taken into consideration that the participants were adult individuals with intellectual disabilities who could imitate, fulfill verbal directions, comply with the rules of the class for one lesson (35-40 min), and have no additional disability. The most to least prompting used in the research is modeling. Modeling in the teaching of sports activities to especially the individuals with normal development is a frequently used method. It should be remembered that individuals with special needs should be given prompts that provide more control, such as physical prompts, in the teaching of sports activities, in terms of the attributes of the participants and the skills that are being taught. This research is similar to the research done by Altenbach-Brennan (2010) in terms of using modeling. Two key factors were taken into consideration in the selection of the skills. One was that participants had never participated in a regular exercise program. The other was that an expert academician's opinions were taken on the selection and inclusion of the dynamic stretching exercises to be taught, the difficulty levels of the exercises and whether the participants would enjoy doing these exercises.

\section{Implications for Future Research}

Based on the results obtained from this study, suggestions for some advanced research can be made. First of all, studies similar to this one which was conducted in the form of a one-to-one teaching style can be conducted again in the form of group teaching or at inclusive sports groups with the participation of normally developing peers or through the training of different skills such as basketball, plates. In addition, as indicated in the literature, a study may be planned to examine the effects of continuing exercise training by adding music at a rhythm appropriate to the exercise process after a certain stage, (e.g., after acquisition), (Jones, Karageorghis, \& Ekkekakis, 2014). Our second recommendation is that in this study dynamic stretching exercises were taught and their effect flexibility and balance measurements of fitness components were evaluated in general. Another implication for further research is to design a study in which the effects of dynamic and static stretching exercises are compared with the inclusion of different fitness components (such as body composition, and agility) into the study. The third research implication was that in the study both trainers and parents reported that participants were very eager to participate in the study, exhibited behaviors that were often happy 
during the teaching of skills and verbal expressions confirming this. From this point of view, the social validity data gathered from the important people in the lives of the participants with the subjective assessment approach can also be collected from the participants themselves in a similar study planned for adult individuals with intellectual disabilities or it may be possible to collect social validity data through social comparison, which is a different approach to social validity. Finally, in this research, a physical education teacher who has been educated about providing systematic teaching to individuals with special needs and about single subject research models taught women with intellectual disabilities by most to least prompting instruction method and all the participants reached the determined level for the skills planned to teach. In addition, in the maintenance sessions held two weeks after the end of the teaching, all of the participants were found to be performing at a satisfactory level in all the skills. According to the literature, systematic teaching processes and single subject researches can also be carried out by researchers, practitioners, parents, general education teachers and branch teachers who have knowledge in this field. In further research, physical education teachers working in inclusive schools can be informed about systematic teaching processes and these teachers can provide systematic teaching planning and practice for the inclusive students. It is thought that the results of such a research can provide important contributions to the relevant literature both in terms of the training process given to the teachers and the experience of the teachers in this process.

\section{References}

Alberto, P. A., \& Troutman, A. C. (1995). Applied behavior analysis for teachers (4th ed.) Englewood Cliffs, NJ: Prentice Hall

Altenbach-Brennan, A. (2010). Teaching aquatic skills to children with autism spectrum disorders. (Master of Science).Southern Illinois University. Department of Rehabilitation Institute. Retrived from http://opensiuc.lib.siu.edu/gs_rp/7

Bartlo, P., \& Klein, P. J. (2011). Physical activity benefits and needs in adults with intellectual disabilities: systematic review of the literature. American Journal on Intellectual and Developmental Disabilities, 116(3), 220-232. https://doi.org/10.1352/1944-7558-116.3.220

Billingsley, F., White, O. R., \& Munson, R. (1980). Procedural reliability: A rationale and an example. Behavioral Assessment, 2, 229-241.

Carmeli, E., Merrick, J., Imam, B., \& Levy, R. (2012). Exercise and sport participation in healthy older adults with intellectual disability-A pilot Study. Health, 4, 769-774. https://doi.org/10.4236/health.2012.429119

Dairo, Y. M., Collett, J., Dawes, H., \& Oskrochi, G. R. (2016) Physical activity levels in adults with intellectual disabilities: A systematic review. Preventive Medicine Reports, 4, 209-219. https://doi.org/10.1016/j.pmedr.2016.06.008

Golubović, S., Maksimović, J., Golubović, B., \& Glumbić, N. (2012). Effects of exercise on physical fitness in children with intellectual disability. Research in Developmental Disabilities, 33(2), 608-614. https://doi.org/10.1016/j.ridd.2011.11.003

Jansen, D. E., Krol, B., Groothoff, J. W., \& Post, D. (2004). People with intellectual disability and their health problems: A review comparative studies. Journal of Intellectual Disability Research, 48(2), 93-102. https://doi.org/10.1111/j.1365-2788.2004.00483.x

Jones, L., Karageorghis, C. I., \& Ekkekakis, P. (2014). Can high-intensity exercise be more pleasant? Attentional dissociation using music and video'. Journal of Sport \& Exercise Psychology, 36, 528-541. https://doi.org/10.1123/jsep.2013-0251

Lin, J. D., Lin, P. Y., Lin, L. P., Chang, Y. Y., Wu, S. R., \& Wu, J. L. (2010). Physical activity and its determinants among adolescents with intellectual disabilities. Research Developmental Disability, 31(1), 263-269. https://doi.org/10.1016/j.ridd.2009.09.015

Lin, P. Y., Lin, L. P., \& Lin, J. D., (2010). Hypertension, hyperglycemia, and hyperlipemia among adolescents with intellectual disabilities. Res. Dev. Disabilities, 31(2), 545-550. https://doi.org/10.1016/j.ridd.2009.12.002

Savucu, Y., Sirmen, B., İnal, S., Karahan, M., \& Erdemir, İ. (2006). Zihin engelli bireylerde basketbol antrenmanının fiziksel uygunluk üzerine etkilerinin belirlenmesi. [Determination the effects of basketball training to the physical fitness of people with mental disabilities] Firat Üniversitesi Sağllk Bilimleri Dergisi, 20(2), 105-113.

Spooner, F., Browder, D. M., \& Mims, P. (2011). Evidence-based practices. In D. M. Browder \& F. Spooner (Eds.), Teaching students with moderate and severe disabilities (pp. 92-125). New York, NY: Guilford.

Sullivan, M. (2005). Educating young children with special needs. Louise Porter (Ed.). Motor Skills (96-116).Sydney: 
Allen and Unwin.

Tawney, J. W., \& Gast, D. L. (1984). Single subject research in special education. Columbus, Ohio: Bell and Howell.

Tekin-İftar, E. (2008). Teaching Children with Behavioral and Learning Problems (s.139-160). Eskişehir: Anadolu Üniversitesi Yayınları

Tekin-Iftar, E., \& Kircaali-Iftar, G. (2006). Özel eğitimde yanlışsız öğretim yöntemleri [Errorless teaching procedures in special education] (3rd ed.). Ankara, Turkey: Nobel Yayın Dağıtım.

Ün, N., Erbahçeci, F., \& Ergun, N. (2001). Mental retarde çocuklarda fiziksel uygunluğun değerlendirilmesi. Romatizma, 6(1).

Wolery, M., Bailey, D. B., \& Sugai, G. M. (1988). Effective teaching: Principles and procedures of applied behavioral analysis with exceptional students. Boston: Allyn and Bacon.

Wu, C. L., Lin, J. D., Hu, J., Yen, C. F., Yen, C. T., Chou, Y. L., \& Wu, P. H. (2010). The effectiveness of healthy physical fitness programs on people with intellectual disabilities living in a disability institution: six-month short-term effect. Research Developmental Disability, 31(3), 713-717. https://doi.org/10.1016/j.ridd.2010.01.013

Yanardağ, M., Birkan, B., Yılmaz, İ., Konukman, F., Ağbuğa, B., \& Lieberman, L. (2011). The effects of least-to-most prompting procedure in teaching basic tennis skills to children with autism. Kinesiology: International Journal of Fundamental and Applied Kinesiology, 43, 44-55.

Yanardağ, M., Ergun, N., Yilmaz, İ., \& Konukman, F. (2008). The effects of most to least prompting procedure on ball playing skills of a child with autism. Research Quarterly for Exercise \& Sport, 79(Suppl. 1), A-87.

Yanardağ, M., Erkan, M., Yılmaz, İ., Arıcan, E., \& Düzkantar, A. (2015). Teaching advance movement exploration skills in water to children with autism spectrum disorders. Research in Autism Spectrum Disorder, 9, 121-129. https://doi.org/10.1016/j.rasd.2014.10.016

Y1lmaz, İ., Birkan, B., Konukman, F., \& Erkan, M. (2005a). Using a constant time delay procedure to teach aquatic play skills to children with autism. Education and Training in Developmental Disabilities, 40, 171-182.

Yilmaz, İ., Birkan, B., Yanardag, M., \& Konukman, F. (2005b). The effects of progressive time delay procedure on teaching basic progression swimming skills for children with autism. Research Quarterly for Exercise \& Sport, 76, (Supplement), A-119.

Yılmaz, İ., Konukman, F., Birkan, B., \& Yanardağ, M. (2010). The effects of most to least prompting on teaching simple progression swimming skill for children with autism. Education and Training in Autism \& Developmental Disabilities, 45, 440-448.

Yılmaz, İ., Konukman, F., Birkan, B., Özen, A., Yanardağ, M., \& Çamursoy, İ. (2010). Effects of constant time delay procedure on the halliwick's method of swimming rotation skills for children with autism. Education and Training in Developmental Disabilities, 45, 124-135.

Yılmaz, İ., Yanardağ, M., Birkan, B., \& Bumin, G. (2004). The effects of swimming training in physical fitness and water orientation in autism. Pediatrics International, 44, 624-626. https://doi.org/10.1111/j.1442-200x.2004.01938.x

Yılmaz, M., Yıldırım, S. H., Serin, G. E, Kısa, S. S., \& Aydın, Ö. (2014). The effectiveness of nutrition and activity programmes for young adults with intellectual disabilities. International Journal of Caring Sciences, 7(2), 449-459.

Zhang, J., Bridget, C., Shihui, C., \& John, L. (2004). The effect of a constant time delay procedure on teaching an adult with severe mental retardation a recreation bowling skill. The Physical Educator, 61, 63-74.

\section{Copyrights}

Copyright for this article is retained by the author(s), with first publication rights granted to the journal.

This is an open-access article distributed under the terms and conditions of the Creative Commons Attribution license which permits unrestricted use, distribution, and reproduction in any medium, provided the original work is properly cited. 